University of Wollongong

Research Online

Faculty of Engineering - Papers (Archive)

Faculty of Engineering and Information

Sciences

$1-6-2007$

\title{
Microstructure Observations of Ag and Ag-Alloy Sheathed Bi2223 Tapes
}

Hua-Kun Liu

University of Wollongong, hua@uow.edu.au

R. Zeng

University of Wollongong, rong_zeng@uow.edu.au

Follow this and additional works at: https://ro.uow.edu.au/engpapers

Part of the Engineering Commons

https://ro.uow.edu.au/engpapers/431

\section{Recommended Citation}

Liu, Hua-Kun and Zeng, R.: Microstructure Observations of Ag and Ag-Alloy Sheathed Bi2223 Tapes 2007. https://ro.uow.edu.au/engpapers/431

Research Online is the open access institutional repository for the University of Wollongong. For further information contact the UOW Library: research-pubs@uow.edu.au 


\title{
Microstructure Observations of $\mathrm{Ag}$ and Ag-Alloy Sheathed Bi2223 Tapes
}

\author{
Hua Kun Liu and Rong Zeng
}

\begin{abstract}
Bi2223 tapes with different configurations of Ag, AgAu7wt\% AgSb0.6wt\% and AgMg0.2wt\% as the precursor and restack sheaths were fabricated using commercial Bi2223 precursor material and powder-in-tube techniques. Short length samples were heat treated at a temperature in the range of $832^{\circ} \mathrm{C}$ to $846^{\circ} \mathrm{C}$ for the first stage (HT 1), followed by a second stage (HT 2) at $825^{\circ} \mathrm{C}$ for $40 \mathrm{~h}$ and slow cooled to $785^{\circ} \mathrm{C}$. An intermediate roll pass was performed between the heat treatment stages. The critical current $\left(I_{c}\right)$ of the tapes was measured at $77 \mathrm{~K}$ in self-field and in fields up to $1 \mathrm{~T}$. The microstructure of the alloy sheaths was examined using optical microscopy, and the Bi2223 filaments after HT 1 and HT 2 were examined using scanning electron microscopy (SEM). It was observed that the sequence of hardness, tensile strength, and critical bend strains from higher to lower levels is very much related to the grain sizes in the restack sheath. $J_{c}$ of the tapes in zero field and in applied field was influenced by the phase composition, core density, grain connectivity, grain alignment and the interface between the $\mathrm{Bi} 2223$ filament and sheath.
\end{abstract}

Index Terms-High temperature superconductors, silver, silver alloys, superconducting wires.

\section{INTRODUCTION}

B i2223 tapes can be used for many applications such as power cables, current leads and coils for magnets, transformers and motors. Since the Bi2223 material is a brittle ceramic, the metal sheathing is needed to impart mechanical, electrical and cryogenic stability to the superconductor [1]-[14]. In applications, tapes sheathed with Ag-alloy have an added advantage because of their better strength compared to pure $\mathrm{Ag}$ [8]-[10]. Pure Ag is too soft compared to the BSCCO superconductor core. It is possible for the hoop stresses to exceed the yield strength of $\mathrm{Ag}$, especially in high-field magnets. In the case of current leads, $\mathrm{Ag}$ sheath is not very attractive since it has a high thermal conductivity, which can cause high coolant consumption. High field magnets require a sufficient mechanical strength of the sheath material to withstand deformation from a large electromagnetic force. Furthermore, the sheath material must provide a strengthening mechanism for the brittle Bi2223 material in the filaments without diminishing the desirable properties of $\mathrm{Bi} 2223$ during processing. It is essential that the composite superconducting tapes be able to withstand the stresses and strains that are encountered during pro-

Manuscript received August 26, 2006. This work was supported by the Australian Research Council and The Australian Superconductor.

The authors are with the Institute for Superconducting and Electronic Materials, The University of Wollongong, NSW 2522 Australia (e-mail: hua_liu@uow.edu.au; rzeng@uow.edu.au).

Digital Object Identifier 10.1109/TASC.2007.899494
TABLE I

TAPES WITH DIFFERENT CONFIGURATIONS OF SHEATHS

\begin{tabular}{cl}
\hline \hline Tape No. & $\begin{array}{c}\text { RESTACK SHEATH/ PRECURSOR SHEATH } \\
\text { Alloying element in wt } \%\end{array}$ \\
\hline 1 & $\mathrm{Ag} / \mathrm{Ag}$ \\
2 & $\mathrm{AgAu} 7 \% / \mathrm{AgAu} 7 \%$ \\
3 & $\mathrm{AgSb} 0.6 \% / \mathrm{Ag}$ \\
4 & $\mathrm{AgAu} 7 \% / \mathrm{AgSb} 0.6 \%$ \\
5 & $\mathrm{AgSb} 0.6 \% / \mathrm{AgAu} 7 \%$ \\
6 & $\mathrm{AgMg} 0.2 \% / \mathrm{AgAu} 7 \%$ \\
7 & $\mathrm{Ag} / \mathrm{AgSb} 0.6 \%$ \\
\hline
\end{tabular}

cessing, handling, and servicing. Mechanical stability is important to ensure that conductor performance is not degraded under operational stresses and strains. It is thus necessary to develop an understanding of the relationship between the mechanical properties, microstructure, and the transport properties of tapes. The mechanical properties [9] and thermal conductivities [10] of Bi2223 tapes fabricated by a powder-in-tube technique with different configurations of $\mathrm{Ag}, \mathrm{AgAu} 7 \mathrm{wt} \% \mathrm{AgSb} 0.6 \mathrm{wt} \%$ and $\mathrm{AgMg} 0.2 \mathrm{wt} \%$ as the precursor and restack sheath materials have been reported. In this paper we report on the relationship between the microstructure observations and the mechanical properties for these tapes.

\section{EXPERIMENTAL}

Ag and Ag-alloy sheathed tapes with 37 filaments were fabricated using commercial Bi2223 precursor material and powder-in-tube (PIT) techniques. The sheath configurations of the tapes are listed in Table I.

Short length samples of tapes were heat treated at a temperature in the range of $832^{\circ} \mathrm{C}$ to $846^{\circ} \mathrm{C}$ for the first stage (HT 1) in order to find the optimized sintering temperature of tapes with different sheath configurations, followed by a second stage (HT 2: $825^{\circ} \mathrm{C}$ for $40 \mathrm{~h}$, slow cooled to $785^{\circ} \mathrm{C}$ and then normal cooled to room temperature) in order to reduce the amount of $\mathrm{Bi} 3221$ and $\mathrm{Bi} 2201$. An intermediate roll pass was performed between the heat treatment stages.

Short length samples of tapes were mounted in both the transverse and longitudinal directions in epoxy, polished to a $1 \mu \mathrm{m}$ finish, and etched in a mixture of $25 \% \mathrm{NH}_{3}$ and $9 \% \mathrm{H}_{2} \mathrm{O}_{2}$ for about 20 seconds. The microstructures of the alloy sheath and the core were obtained by LEICA optical spectroscope and Cambridge Stereoscan S440 scanning electron microscope, respectively (SEM). Samples for SEM were mounted in epoxy so that both longitudinal and transverse-cross sections were visible. The samples were polished to a $1 \mu \mathrm{m}$ finish and coated with $\mathrm{Au}$. 
TABLE II

MEASUREd PROPERTIES OF OPTIMIZED SHORT SAMPLES WITH OPTIMIZED J $(77 \mathrm{~K}, 0 \mathrm{~T})$

\begin{tabular}{|c|c|c|c|c|c|c|}
\hline $\begin{array}{l}\text { Tape } \\
\text { No. }\end{array}$ & $\begin{array}{l}\text { BEND } \\
\text { STRAIN } \\
\text { E }_{\text {CRIT }}(\%)\end{array}$ & $\begin{array}{l}\text { HARDNESS } \\
\text { (HV) }\end{array}$ & $\begin{array}{l}\text { STRESS } \\
\text { (MPA) }\end{array}$ & $\begin{array}{l}\text { BI2223 } \\
\%(\text { VOL) }\end{array}$ & $\begin{array}{l}\text { BI2212 } \\
\%(\text { VOL })\end{array}$ & $\begin{array}{l}\text { BI3221 } \\
\%(\mathrm{VOL})\end{array}$ \\
\hline 1 & 0.33 & $\sim 60$ & $\sim 50$ & 94.3 & 3.8 & 1.9 \\
\hline 2 & 0.28 & $\sim 60$ & $\sim 60$ & 84.3 & 12.2 & 3.5 \\
\hline 3 & 0.42 & $\sim 70$ & $\sim 100$ & 95.2 & 3.8 & 1.0 \\
\hline 4 & 0.25 & $\sim 50$ & $\sim 70$ & 82.9 & 12.0 & 4.3 \\
\hline 5 & 0.47 & $\sim 70$ & $\sim 100$ & 91.7 & 4.6 & 3.7 \\
\hline 6 & 0.73 & $\sim 90$ & $\sim 150$ & 88.5 & 10.6 & 0.9 \\
\hline 7 & 0.32 & $\sim 50$ & $\sim 60$ & 94.8 & 3.1 & 2.1 \\
\hline
\end{tabular}

* The volume fraction of Bi2201 in all tapes is $<1 \%$

\section{RESULTS AND DISCUSSION}

Table II lists the measured properties of 37 filament Bi2223 tapes with 7 different configurations of restack sheath/precursor sheath, i.e. Ag/Ag (tape 1), AgAu7wt\%/AgAu7wt\% (tape 2), AgSb0.6wt\%/Ag (tape 3), AgAu7wt\%/AgSb0.6wt\% (tape 4), AgSb0.6wt\%/AgAu7wt\% (tape 5), AgMg0.2wt\%/AgAu7wt\% (tape 6) and $\mathrm{Ag} / \mathrm{AgSb} 0.6 \mathrm{wt} \%$ (tape 7) at optimized $\mathrm{J}_{\mathrm{c}}$ (77 $\mathrm{K}, 0 \mathrm{~T})$. The volume fractions (calculated from XRD data) for $\mathrm{Bi} 2223, \mathrm{Bi} 2212, \mathrm{Bi} 2201$ and $\mathrm{Bi} 3221$ phases in the tapes with optimized $\mathrm{J}_{\mathrm{c}}$ are $84-95 \%, 3-12 \%,<1 \%$ and $1-6 \%$, respectively.

The sequence of critical bend strains, $\varepsilon_{\text {crit }}$ (bend strain when $\mathrm{I}_{\mathrm{c}} / \mathrm{I}_{\mathrm{co}}=0.95$ ) of the tapes is $0.73 \%$ for tape 6 (with restack sheath $\mathrm{AgMg}$ ), $0.42 \%$ and $0.47 \%$ for tapes 3 and 5 (both having the restack sheath $\mathrm{AgSb}$ ), $\sim 0.3 \%$ for tapes 1 and 7 (both having the restack sheath $\mathrm{Ag}$ ), and $0.28 \%$ and $0.25 \%$ for tapes 2 and 4 (both having the restack sheath $\mathrm{AgAu}$ ).

The sequence of the sheath hardness and tensile strength from higher to lower levels is tape 6, tapes 3 and 5, and the others (having $\mathrm{Au}$ or $\mathrm{Ag}$ in the restack sheath), similar to the ranking of bend strain tolerance.

The relationship between $\mathrm{J}_{\mathrm{c}}$ and magnetic field is characteristic of multifilament Bi2223 tapes fabricated using a PIT technique. No conclusive correlation between alloy type or configuration and $\mathrm{J}_{\mathrm{c}}$ performance in magnetic fields is found. It is believed that higher $\mathrm{J}_{c}$ and better performance in magnetic fields are related to the phase composition, core density, grain connectivity, grain alignment and the interfaces between the filament and sheath.

\section{A. Grain Size of Alloy Sheath}

The optical microscope images (Fig. 1(a)-(g)) shows very large grains in restack sheath $\mathrm{Ag}$ (tapes 1 and 7), large grains in $\mathrm{AgAu}$ (tapes 2 and 4), although they are not clear in the figure $\mathrm{Au}$ was not etched in the solution used, small grains in $\mathrm{AgSb}$ (tapes 3 and 5) and very small grains in $\mathrm{AgMg}$ (tape 6). The measured average grain diameters of $\mathrm{Ag}, \mathrm{AgAu}, \mathrm{AgSb}$ and $\mathrm{AgMg}$ were 48.0, 29.3, 26.0, and $3.9 \mu \mathrm{m}$, respectively. It is believed that the smaller grain size in the Ag alloys contributes to the higher strength of the alloy-sheathed tapes compared to that of Ag tape. The larger grain sizes can not endure high bending. The sequence of hardness, tensile strength, and critical bend strains from higher to lower level is tapes $6 ; 3 \& 5 ; 2 \& 4 ; 1 \& 7$, which

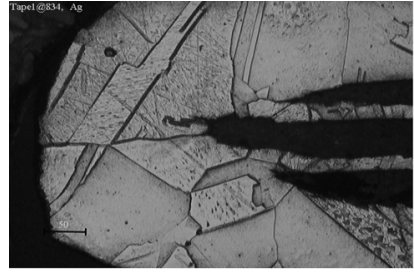

(a)

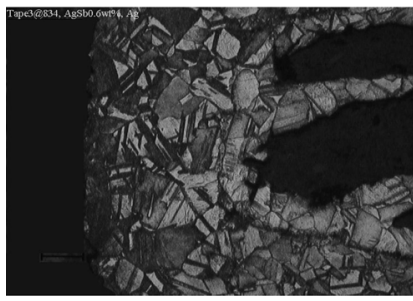

(c)

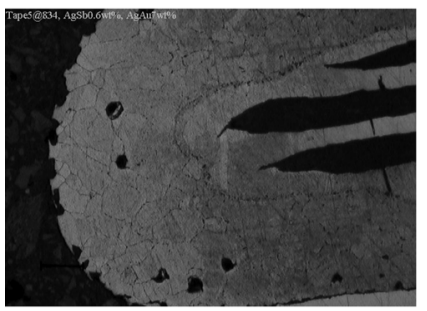

(e)

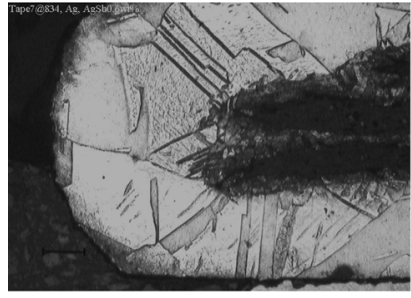

(g)

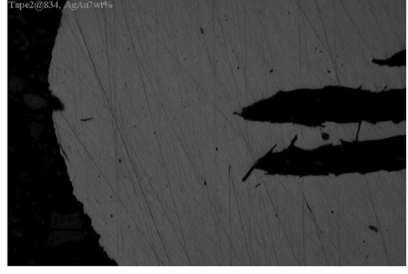

(b)

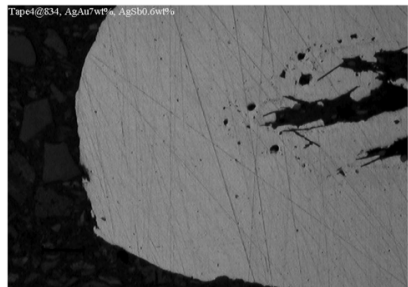

(d)

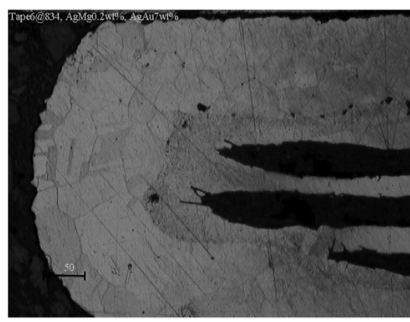

(f)
Fig. 1. Optical images of Ag and Ag-alloy sheath for 7 tapes: tape 1 (a), tape 2 (b), tape 3 (c), tape $4(\mathrm{~d})$, tape 5 (e), tape 6 (f) and tape $7(\mathrm{~g})$

is very much related to the grain sizes in the restack sheath. On the other hand, some black particles are found in tapes 3, 4 and 5 , which may indicate that there is a reaction between $\mathrm{Sb}$ and oxygen introduced during processing.

The large Sb oxide grains may reduce the tolerance to bending strain, as there is much more Sb oxide in tape 3, and the tolerance to bending strain of tape 3 is a little weaker than that of tape 5 .

\section{B. Interface Between Core and Sheath}

It can be seen that the BSCCO core has grown into the Ag-alloy sheath in the form of branches or spikes (Fig. 1) with some branches connecting together and forming islands. A lot of outgrowths are found in tape 4 and less outgrowths in other tapes.

When AgSb alloy is used as the precursor material, a reaction layer at the interface of the precursor and the core (Fig. 1(g)) and black dots (Fig. 1(d)) located at the interface of the precursor and restack sheath are found due to the reaction between $\mathrm{Sb}$ and the BSCCO core. When AgSb or AgMg alloy is used as 
the restack material, the black dots ( $\mathrm{Sb}$ oxide) are found in the restack sheath (Fig. 1(e)) or at the interface (Fig. 1(f)) of the precursor and restack sheath due to the reaction of $\mathrm{Sb}$ or $\mathrm{Mg}$ with oxygen diffused from the BSCCO core or in air that was trapped during the tube packing process.

$\mathrm{Mg}$ and $\mathrm{Sb}$ oxides may result in lattice distortions and thus improve the mechanical properties. Matching the hardness of the sheath material and the BSCCO core can clearly improve the stability of the interface during rolling, even though the tape is annealed before rolling. The coefficient of thermal expansion of the oxide is lower than that of silver, so when the tape is heated tensile stress is exerted on the oxide and cracking can occur if the ceramic core is weak.

\section{Secondary Phases in Superconducting Core}

Fig. 2(a)-(g) shows SEM images of tapes after HT 1. It is clearly seen that there is considerable liquid phase in tape 4; less in tapes 3,5 and 6; and very much less in tapes 1,2 and 7. The second phase in tapes 1,2 and 7 is much less than in tape 4, and less than in tapes 3,5 and 6 . The particle sizes of tapes 3,5 and 6 are smaller than in tapes 1, 2 and 7. In tape 4, the filaments are all melted together and have lost their regular alignment. The major phase was Bi2212 in the green tapes, and there was almost no Bi2223 phase, while after HT 1 about $80 \%$ of the phases were converted into Bi2223 phase with the rest remaining as impurity phases in most cases.

Fig. 3(a)-(g) shows SEM images of the final tapes. After intermediate rolling and HT 2, the superconducting cores become denser and better aligned compared with the tapes after HT1. They also show a large amount of Bi2223 phase (>90\%), a small amount of Bi2212 $(<12 \%)$, and very small amount of $\mathrm{Bi} 2201(<1 \%)$ and $\mathrm{Bi} 3221(<6 \%)$ for tapes $1,3,5$ and 7 under optimized conditions. Tapes 2, 4 and 6 contain relatively less Bi-2223 phase and more impurity phases than tapes 1, 3, 5 and 7. In Fig. (3g), it can be seen that Bi2223 phase (grey) is present in a large amount $(95 \%)$, while there are very small amount $(3 \%)$ of Bi2212 (thin white layer) and Bi3221 (2\%). This is because Bi2201 was converted into superconducting phase during sintering at lower temperature $\left(810^{\circ} \mathrm{C}-825^{\circ} \mathrm{C}\right)$ [11], and slow cooling eliminated Bi3221 [12].

SEM images show the process of Bi2223 grain growth and grain connection by comparison of tapes after HT 1 and after HT 2. A higher volume percentage of Bi2223, a lower volume percentage of impurity phases, higher density and better grain alignment in the superconducting core are achieved, which are all responsible for higher $J_{c}$ values. We believe that the degradation of $\mathrm{J}_{\mathrm{c}}$ in higher magnetic field is greatly influenced by microstructural features such as micro-cracks and porosity, $\mathrm{Ag}-\mathrm{Au}$ system is more stable than the $\mathrm{Ag}-\mathrm{Mg}$ and $\mathrm{Ag}-\mathrm{Sb}$ systems since $\mathrm{Au}$ is completely soluble in a solid solution with $\mathrm{Ag}$ and raises the melting temperature and increases the electrical resistivity when added to $\mathrm{Ag}$, moreover, Au has less affinity to oxygen than the Ag and any elements in the BSCCO, so that there is no detrimental effect on the superconducting properties. If a long sintering is used for processing Bi2223 tapes, $\mathrm{Mg}$ or Sb oxides may form at the interface between the precursor sheath and core, which could degrade the superconducting properties.

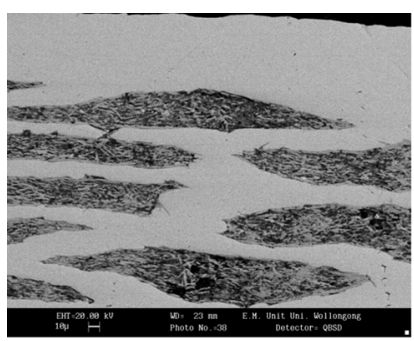

(a)

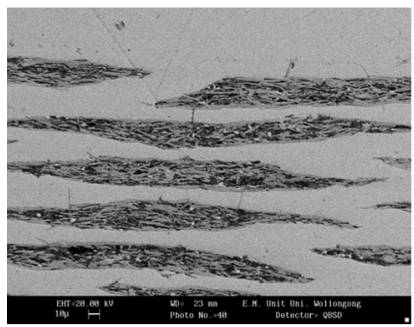

(c)

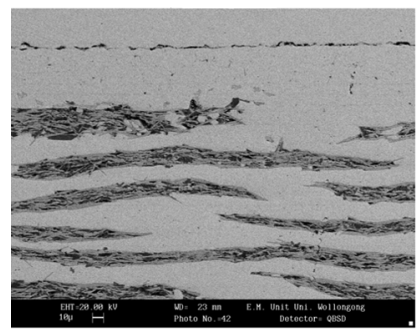

(e)

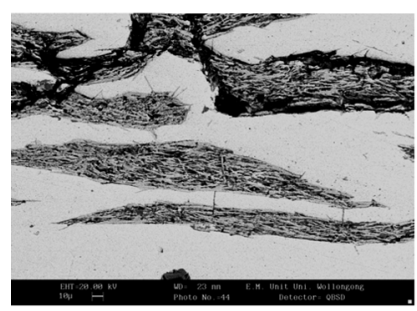

(g)

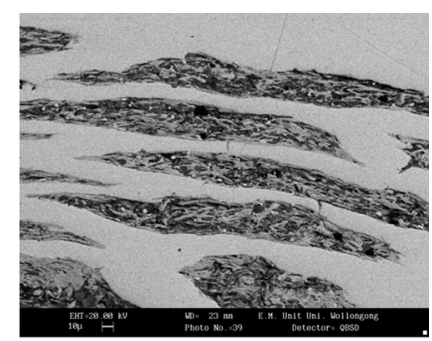

(b)

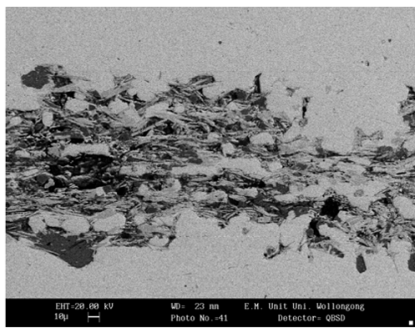

(d)

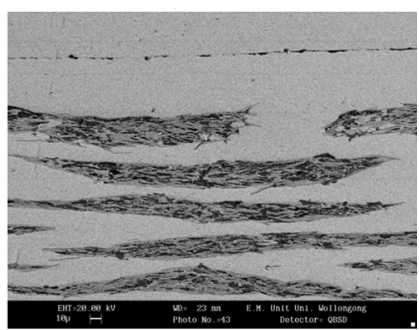

(f)
Fig. 2. SEM images of tapes after HT 1. (a) Tape 1; (b) tape 2; (c) tape 3; (d) tape 4 ; (e) tape 5; (f) tape 6; (g) tape 7.

\section{CONCLUSIONS}

37 filament Bi2223 tapes with different configurations of Ag, $\mathrm{AgAu} 7 \mathrm{wt} \% \mathrm{AgSb} 0.6 \mathrm{wt} \%$ and $\mathrm{AgMg} 0.2 \mathrm{wt} \%$ as the precursor and restack sheaths were fabricated using commercial Bi2223 precursor material and the powder-in-tube technique.

From the optical images of the sheaths we have found that the sequence of hardness, tensile strength, and critical bend strains from higher to lower levels for the tapes is very much related to the grain sizes of the restack sheath materials. Tapes with like restack sheath materials have similar bending strain properties. The variation in the bend strain tolerance of the tapes is consistent with the results of the hardness and tensile strength measurements. $\mathrm{AgMg}$ with very small particles dispersed in an $\mathrm{Ag}$ matrix increases hardness significantly due to dispersion hardening. Smaller AgSb particles in an Ag matrix also play an important role in enhancing the hardness, while $\mathrm{AgAu}$ increases the resistivity but is not effective in increasing the hardness. 


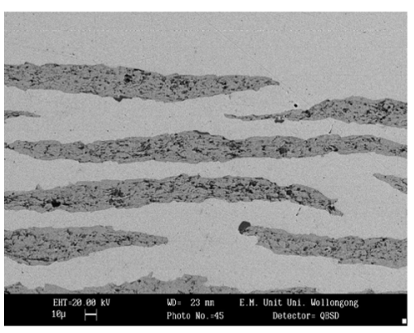

(a)

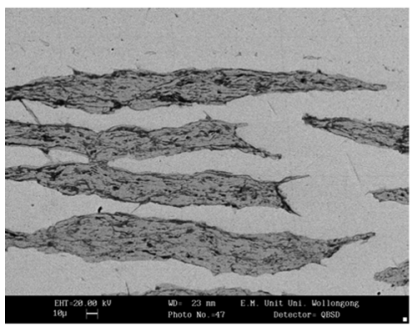

(c)

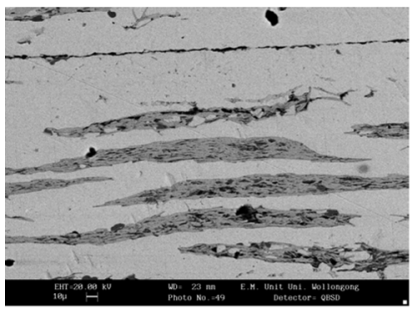

(e)

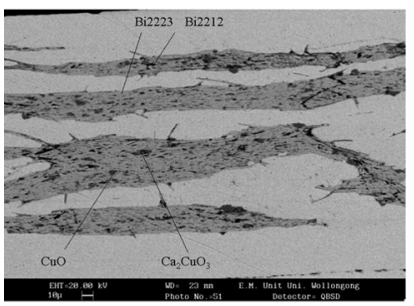

(g)

Fig. 3. SEM images of tapes after HT 2. (a) Tape 1; (b) tape 2; (c) tape 3; (d) tape 4; (e) tape 5; (f) tape 6; (g) tape 7.

$\mathrm{AgMg}$ and $\mathrm{AgSb}$ alloys as restack materials in Bi2223 tapes can extraordinarily improve the mechanical properties of tapes. The improved mechanical properties are probably due to dispersion hardening or grain size strengthening.

SEM images of the tapes indicate that higher $\mathrm{J}_{\mathrm{c}}$ and better performance in magnetic fields are related to the phase compo- sition, core density, grain connectivity, grain alignment and the interfaces of the filament and sheath.

\section{ACKNOWLEDGMENT}

The authors thank J. Volf, Z.M. Zhang, and M. Apperley who made the tapes.

\section{REFERENCES}

[1] R. Navarro, "Silver alloys used in composite BSCCO tapes: Development of electrical and mechanical properties during manufacture," $\mathrm{Su}$ percond. Sci. Technol., vol. 13, p. R147, 2000.

[2] T. Sasaka, K. Nomura, J. Kuma, H. Fujishiro, M. Ikebe, and K. Noto, "Characteristics of Ag-Au alloy sheathed Bi-Pb-Sr-Ca-Cu-O superconducting tapes for current leads," Appl. Phys. Lett., vol. 64, no. 10, p. 1304, 1994.

[3] J. Yoo, H. Chung, J. Ko, and H. Kim, "Long-length processing of Bi-2223 tapes made by using Ag-alloys sheath," IEEE, Trans. Appl. Supercond., vol. 7, no. 2, pt. 2, p. 1837, 1997.

[4] L. Martini, F. Barberis, R. Berti, L. Bigoni, F. Curcio, and G. Volpini, "Optimisation of multilayered Bi-2223/Ag-Au conductors for current lead applications," International Journal of Mordern Phys. B., vol. 13, no. 9-10, p. 1357, 1999.

[5] M. Quilitz and W. Goldacker, "Oxygen exchange in Bi(2223) tapes with Ag and alloyed AgMg sheaths monitored by a thermogravimetrical relation method," Supercond. Sci. Technol., vol. 11, p. 577, 1998.

[6] M. Dhallé, R. Passerini, E. Giannini, G. Witz, J.-Y. Genoud, Y. Huang, $\mathrm{X}$.-D. Su, and R. Flükiger, The Formation Mechanism of $\mathrm{Bi}, \mathrm{Pb}(2223)$ Outgrowths in Multi-Filamentary Tapes.

[7] M. H. Apperley, R. Zeng, F. Damann, and G. McCaughey, "Properties of Ag-Mg alloy sheathed Bi-2223 tapes," Cryogenics, vol. 40, p. 319, 2000.

[8] H. P. Yi, L. Liu, X. H. Song, W. Kang, L. Liu, J. S. Zhang, Q. Liu, Z. Han, and K. Zheng, "Effect of intermediate rolling on the microstructure and $\mathrm{J}_{\mathrm{e}}$ performance of Ag-sheathed Bi-2223 tapes," Physica C, vol. 419, p. 109, 2005.

[9] H. K. Liu, Z. M. Zhang, R. Zeng, J. Horvat, and M. Apperley, "A comparison of $\mathrm{Ag}$ and $\mathrm{Ag}$-alloy sheathed $\mathrm{Bi}-2223$ tapes," IEEE, Trans. Appl. Supercond., vol. 13, p. 3004, 2003.

[10] S. H. Jang, J. H. Lim, J. H. Kim, B. K. Ji, J. H. Hoo, W. S. Nan, J. Volf, H. K. Liu, and M. Apperley, "Characterisation of thermal conductivity and mechanical properties of $\mathrm{Ag}$-alloy sheathed $\mathrm{Bi}(\mathrm{Pb})-\mathrm{Sr}-\mathrm{Ca}-\mathrm{Cu}-\mathrm{O}$ superconductor tape," IEEE, Trans. Appl. Supercond., vol. 13, p. 2956, 2003.

[11] R. Zeng, Y. C. Guo, Y. Tanaka, J. Horvat, M. Ionescu, T. P. Beals, and M. Apperley, "Effect of the phase formation of Bi-2223 in some Ag-alloy sheathed PIT tapes," Pyhsica C, vol. 307, p. 229, 1998, H. K. Liu and S. X. Dou.

[12] E. Guilmean, B. Andrzejewski, and G. Desgardin, "The effect of Bi2201 phase on the intergranular critical field and current density in Bi2223 superconductors," Physica C, vol. 377, p. 304, 2002.

[13] W. G. Wang, J. Horvat, B. Zeimetz, H. K. Liu, and S. X. Dou, "Effect of $(\mathrm{Bi}, \mathrm{Pb})_{2} \mathrm{Sr}_{2} \mathrm{Ca}_{2} \mathrm{Cu}_{3} \mathrm{O}_{10}$ phase on critical current density of $\mathrm{Ag} /(\mathrm{Bi}, \mathrm{Pb})_{2} \mathrm{Sr}_{2} \mathrm{Ca}_{2} \mathrm{Cu}_{3} \mathrm{O}_{10}$ tapes," Physica C, vol. 291, p. 1, 1997.

[14] T.-M. Qu, Z. Han, and R. Flükiger, "Phase evolution during post-annealing and its influence on critical current of $(\mathrm{Bi}, \mathrm{Pb})-2223$ tapes," Physica C, vol. 444, p. 71, 2006. 